ALPHA No 26 / Julio 2008 (167-189)

ISSN 0716-4254

http://alpha.ulagos.cl

\title{
PROYECTOS DE LA ELITE CHILENA DEL SIGLO XIX (I) ${ }^{1}$ \\ Chile's 19th century elite's projects
}

\author{
Jorge Pinto Rodríguez*
}

\section{Resumen}

Examen de los proyectos con que la elite chilena del siglo XIX gobernó el país. La hipótesis es que hubo un proyecto original levantado por quienes se instalan en el poder después de la Independencia que se sostuvo en el orden, la centralización del poder, la voluntad de desarrollarnos por nosotros mismos, de espaldas a cualquier proyecto sudamericano, y materialmente sostenido en las exportaciones de nuestras materias primas. Este proyecto fue cuestionado por una generación más liberal, formada en los años 40, que llega al poder en los años 60. Admiradores del positivismo, aquellos jóvenes vieron en Europa el modelo a seguir. Para ellos, el progreso, meta final que querían lograr, fue asociado a Francia, Inglaterra y, en algunos casos, a Estados Unidos, cuyas huellas pretenden seguir, sin considerar las particularidades de Chile. Con cierta insensibilidad social e incapaz de atender las demandas de los grupos subalternos, este proyecto arrastró al país a la crisis que lo sacudió a fines del siglo XIX y comienzos del XX.

Palabras Claves: Chile, elite, proyectos.

\section{Abstract}

This article discusses projects with which the elite ruled Chile in the 19th century. According to the author, there was an original project led by those who ruled the country after the Independence; it was based on order, power centralization, and Chilean people's own ideas on self-improvement irrespective of any other South American project and materially supported by Chilean raw materials exports. This Project was questioned by a more liberal generation rising in the 1840s and taking over power in the 1860s. Being admirers of positivism, youngsters looked at Europe as a model to be followed. As their ultimate goal, they associated progress with France, England, and in some cases, the U.S.A. They wanted to follow these countries' footsteps regardless of Chile's national characteristics. With little social sensitivity and unable to meet the demands of subaltern groups, this project led the country to the crisis at the turn of the century.

Key Words: Chile, elite, projects.

${ }^{1}$ Este artículo —elaborado en el marco del proyecto CONICYT $N^{\circ} 1020289$, dirigido por Carmen Norambuena y del cual el autor fue coinvestigador - consta de dos partes que serán publicadas sucesivamente en Alpha $\mathrm{N}^{\circ} 26$ y Nº 27. 


\section{Jorge Pinto Rodríguez}

\section{INTRODUCCIÓN}

Evocando la Revolución de 1851, Daniel Riquelme, el agudo escritor de la segunda mitad del siglo XIX, dejó en evidencia la distancia que existía entre los proyectos de los grupos minoritarios que se disputaban el poder en Chile y los sectores populares. Tras los conspiradores, escribe Riquelme,

seguían llegando centenares de curiosos, en gran parte sirvientes de casas que iban al Mercado, y en cuanto se imponían de la novedad desaparecían a repartirla, trayendo a otros nuevos. El pueblo miraba con simpatías ese aparato de combate; pero desde lejos, sin mezclarse en nada, salvo unos ciento o ciento cincuenta artesanos”.

"Recuerdo, como si lo estuviera viendo, agrega Riquelme, a un joven que llegó armado con una escopeta... [y que] ... tomó la palabra, diciendo que iba a derramar su sangre por la libertad y los santos derechos del pueblo oprimido”.

— ¡De vosotros! — concluyó el joven, extendiendo los brazos hacia la turba”.

—¿QQué negocio irá a hacer este futre?- gritó un roto, y esta pedrada anónima mató al orador (1966:78).

El relato de Riquelme, a medio camino entre la ficción y la realidad, muestra la apatía de los grupos subalternos frente a las disputas de la elite. Inspirados en los sucesos de París de 1848, los representantes más jóvenes de esa elite intentaban, al promediar el siglo XIX, replicar en Santiago las movilizaciones que presenciaron a orillas del Sena, enteramente de espaldas a la realidad nacional. Nacidos poco después de la Independencia y herederos naturales del poder que conquistaron sus padres, crecieron en un ambiente que atribuyó a España y a la herencia colonial el atraso de nuestros países, atraso que ellos consideraban podía superarse si se imitaba a los países europeos ubicados al norte de la península ibérica. Esa Europa se convirtió en un modelo y los europeos de aquellas latitudes en el ejemplo a seguir. Todo lo que nos aproximara a España y, más tarde, a nuestras raíces indígenas, debía olvidarse, para dar cabida a ese hombre nuevo que nos conduciría por los caminos de la felicidad. Con evidente orgullo y resumiendo una apreciación que muchos hombres de la época compartieron, Vicente Pérez Rosales decía que nuestra primera virtud consistía en parecernos al Viejo Mundo. Chile, agregaba Pérez Rosales, es una "verdadera fracción europea trasplantada a 4.000 leguas de distancia en el otro hemisferio". ${ }^{2}$

${ }^{2}$ Citado por Javier Pinedo. "Visión de Chile en Vicente Pérez Rosales”, en Mario Berríos y otros. El pensamiento en Chile, 1830-1910. Santiago: Nueva América, 1987, 68. Para una información más completa acerca de nuestras elites en el siglo XIX, Cfr. Rafael Sagredo. 
Naturalmente, no todos nuestros intelectuales y dirigentes políticos pensaban del mismo modo. Sin embargo, poco a poco la idea de imitar a Europa se convirtió en una de las principales metas para los grupos más influyentes de nuestra sociedad. Allí estaba la clave del éxito. Si repetíamos la experiencia europea entraríamos por la puerta ancha a la Historia, a la felicidad y al progreso.

\section{LA GÉNESIS DE LOS PROYECTOS MODERNIZADORES}

Entrar a la Historia y superar el oscurantismo colonial era, en cierta medida, lo que hoy llamamos modernizar al país. Ésa fue la tarea que se propusieron quienes encabezaron la Independencia y que, hacia 1820, se perfilaban como sus nuevos conductores. El proceso que vivió Chile en el resto del siglo XIX hace presumir que para alcanzar la meta los grupos dirigentes identificaron tres tareas específicas, de cuyo logro dependía el futuro: en primer lugar, establecer una estructura de poder que les permitiera reemplazar al viejo sistema colonial; en segundo lugar, insertar a la economía nacional en el concierto de la economía mundial; $y$, por último, identificar un modelo de país y nación al cual adherir.

La construcción del Estado y la Nación y la inserción de la economía chilena en la economía mundial. Esta tarea implicaba construir el Estado y la Nación. Y a eso se abocaron nuestros dirigentes en los años posteriores a la Independencia. Y no era tarea fácil. Había que perfilar el territorio, definir su componente humano, establecer la normativa jurídica que requiere todo Estado y establecer su aparato burocrático-militar. Un cúmulo de tareas en medio del desconcierto que había provocado la Guerra de la Independencia, el desconocimiento de la realidad nacional y las rivalidades de los grupos que se disputaban el poder. Sin embargo, no se partía de cero.

Desde fines del siglo XVIII, miembros de los grupos vinculados al poder y a la intelectualidad colonial habían iniciado una apertura a las nuevas ideas que circulaban en Europa, hasta entonces miradas con cierta distancia. Fueron los jóvenes quienes dieron los pasos más decisivos. Cuidadosamente educados en Santiago o en Lima y con alguna experiencia en Europa, pudieron observar al país con criterios muy distintos a los de sus padres o sus abuelos. Era, además, una época de cambios provocados por las reformas borbónicas y las medidas que impulsaban gobiernos progresistas como el de Ambrosio O’Higgins. En un clima de cierta efervescencia política e

“Elites chilenas del siglo XIX. Historiografía”, en Cuadernos de Historia No 16, Santiago, Universidad de Chile (1996), 103-132 y Gabriel Salazar y Julio Pinto. Historia contemporánea de Chile. Actores, identidad y movimiento. Tomo II. Santiago: Lom, 1999, 31: 64. 


\section{Jorge Pinto Rodríguez}

intelectual se fueron fraguando los primeros proyectos para un país que se acercaba a su independencia.

En los primeros años del siglo XIX don Juan Egaña anticipó una idea que paulatinamente se fue generalizando y que gravitó al momento de pensar el Chile del futuro. En una especie de diagnóstico, reconoció las bondades del territorio; pero, a la vez, las debilidades de su población. Chile - escribía en 1803 - es una especie de dragón incapaz de aprovechar sus riquezas por la falta de brazos y escasas luces de sus habitantes.

La idea de un país cuyo territorio fue privilegiado por la naturaleza, pero con una población que está lejos de corresponder a las virtudes de aquella fecundidad caló profundamente en la intelectualidad chilena de comienzos del siglo XIX. Numerosos jóvenes que viajaron a Europa, transformaron la nostalgia en una imagen estereotipada del territorio lejano, que les hizo presumir que ningún rincón del mundo se podía igualar a esta larga y angosta faja de tierra que se recuesta sobre el Pacífico sur. El mito de la Cordillera de los Andes, de los campos bordados de flores, de un océano que nos baña con generosidad y de una variedad de climas que hacen del país una copia feliz del Edén, se fue convirtiendo en el punto de partida a la hora de proyectar el país. Lamentablemente, toda la generosidad de estos jóvenes para recordar el territorio se agotó cuando se trató de su población. Desde un comienzo expresaron una imagen más bien negativa del chileno, asociando sus actitudes y costumbres a defectos que frenaban el progreso y obligaban a la clase dirigente a remediarlos.

Al comienzo, esta idea se planteó con cierta timidez. Cuando en los albores de la República el propio Juan Egaña intentó sentar las bases del Estado, depositó en la Constitución de 1823 buena parte de la responsabilidad de sacar adelante al país en los pobladores comunes y corrientes. Aunque reconoció que se debía moralizarlos, su Constitución era una muestra de confianza en las costumbres del chileno, las cuales —plena-mente reglamentadas por la misma Carta Fundamental- contribuirían al engrandecimiento de la patria. Si la Constitución era exitosa y conseguía transformarse en un código moral que convirtiera las costumbres en virtudes cívicas, Chile podía confiar en los chilenos. ${ }^{3}$

Se debía, en todo caso, mantenerse alerta. Si bien los chilenos podían adquirir virtudes cívicas, se debían evitar los riesgos. El mismo Juan Egaña,

\footnotetext{
${ }^{3}$ Cfr. “Capítulo XII de la Constitución de 1823”, en Luis Valencia Avaria. Anales de la República. Santiago: Andrés Bello, 1986. Estas ideas ya estuvieron presentes en la Constitución de 1818 y en la prensa de la época, cuyos articulistas también confiaron en la moralidad ciudadana moldeada por el Estado. Para la Constitución de 1818, Cfr. Valencia, Avaria, op. cit.., y para los artículos de prensa, Cfr. Colección de Antiguos Periódicos Chilenos. Santiago: Biblioteca Nacional, 1954-1966 (en adelante CAPCh).
} 
—en un documento elaborado en 1810 - proponía impedir el ingreso de negros porque, en su opinión, eran "viciosos” y podían arrastrar a la plebe a conductas reñidas con los principios del buen ciudadano. El temor al chileno del bajo pueblo estuvo presente en el pensamiento de la elite, desde la génesis de la República, alentando medidas que demuestran que los proyectos de futuro no podían pasar por alto las debilidades de nuestra población. ${ }^{4}$ Ésta fue la razón por la cual los proyectos de la elite fueron tan excluyentes, centrados sólo en sus experiencias e incapaces de conceder historicidad a los grupos subalternos, por los cuales siempre sintieron una mezcla de temor con menosprecio (Barros y Valdés, 1978; Fernández, 2003).

¿Qué caracterizó al primer proyecto político de los grupos dirigentes en su afán por modernizar al país y que habría cristalizado en lo que algunos historiadores llaman el “orden portaliano”? Hay varias ideas que están en la matriz de este proyecto.

En primer lugar, se consideró que la clave del éxito estaba en el orden, un orden que - según Portales- terminaría imponiéndose casi de un modo natural por el "peso de la noche", factor clave que explicaría el éxito de su proyecto político. ${ }^{5}$ En términos generales, nuestra elite pensó que el siglo XIX era el siglo del progreso y que correspondía a los gobiernos facilitar su llegada. El progreso, pensaban los grupos más conservadores, requería de libertad; pero, por sobre todas las cosas, de orden. Sin orden no hay progreso. La libertad ilimitada en política se llama anarquía y ésta es la barrera más nefasta para alcanzarlo, se sostenía en El Ferrocarril del 7 de enero de 1856. El progreso y la inseguridad se excluyen. Sólo la paz hace causa común con el progreso. A juicio de los miembros ilustrados de nuestra elite, ésta era una virtud que en América Latina sólo Chile podía exhibir. Allí estaba su

\footnotetext{
${ }^{4}$ A pesar de estas aprensiones, hay que reconocer que algunos miembros de la elite y de la emergente clase política creyeron que era posible depositar más poder en los grupos subalternos en una especie de República distinta a la conocida durante la Colonia. Carrera y Freire encabezaron esta tendencia; pero su falta de capacidad para concederle contenido político terminó por hacerla sucumbir frente a los proyectos de los grupos más conservadores y menos dispuestos a establecer cambios que pusieran en peligro sus intereses. Cfr. Gabriel Salazar. Construcción de Estado en Chile (1800-1837). Santiago: Sudamericana, 2005.

${ }^{5}$ Alfredo Jocelyn-Holt ha comentado largamente esta expresión de Portales. Cita una carta en la cual Portales dice que "la tendencia casi general de la masa al reposo es la garantía de la tranquilidad pública”. Para Portales "el peso de la noche” era la suma del viejo orden colonial, que se mantuvo casi intacto después de la Independencia. Cfr. Alfredo Jocelyn-Holt. El peso de la noche. Santiago: Planeta/Ariel, 1998: 27 y 148. En otro documento de la época se reconoció el apego de los chilenos al orden, sencillez y probidad, destacando valores positivos que no aparecen con frecuencia en la documentación de la entonces. En este documento se atribuyen estos valores a la guerra de Arauco y a la ausencia de riquezas, que siempre estimulan las discordias. Cfr. Motivos que ocasionaron la instalación de la Junta de Gobierno en Chile y el Acta de la misma. Cádiz: Imprenta de la Junta Superior de Gobierno, 1811.
} 


\section{Jorge Pinto Rodríguez}

singularidad. Por encima de la libertad, su grandeza radicaba en el orden de su gente, valor que le concedía una cierta superioridad frente a sus vecinos. "Tenemos autoridad para observar lo que ocurre en el continente - escribía un articulista de El Ferrocarril, el 9 de enero 1856 - porque mientras la mayoría de las repúblicas de Sudamérica se encuentran abatidas por luchas intestinas, revoluciones, contrarrevoluciones, fusilamientos y proscripciones, en Chile esas cosas no ocurren". "Eso mismo —agregaba otro articulista de $E l$ Ferrocarril en febrero de 1856 - nos ha permitido sobrepasar a esas repúblicas y aproximarnos al nivel de las culturas más avanzadas”. Toda la elite chilena, sin distinciones, abogó y celebró este orden, desde Portales hasta los liberales más acérrimos. No sin razón, María Angélica Illanes (2003) ha sostenido que Chile escribió su historia conservadora y/o positivista (entiéndase siglo XIX), "sobre una categoría denominada simplemente 'orden', al que se le ha otorgado el status de mito institucional”, aunque se trate de un orden basado en la censura y en la falta de libertad de expresión que sólo atendió los intereses de la propia elite.

En segundo lugar, se impuso un principio unitario y centralista que impidió a las regiones insertarse en los procesos que se estaban iniciando en igualdad de condiciones respecto de Santiago. En opinión de Gabriel Salazar (2005), una de las grandes deficiencias de este proyecto fue el aplastamiento de la sociedad civil, conminada a someterse a un poder centralizado que se manejaba desde la cúpula del poder con el apoyo del aparato militar que creó Portales. Sin restarle validez a esta apreciación, no cabe dudas que el "orden portaliano” aplastó también a las regiones. Ya desde esa época se miraba con cautela a los poderes locales o regionales, cuyas aspiraciones ponían en peligro el principio unitario y centralista que se impuso después de la derrota de los grupos disidentes en Lircay. "El gobierno interior de las provincias es monstruoso", declaraban en 1831 sus diputados de la Gran Convención Constituyente Agustín de Vidal, F.A Elizalde y M. J. Gandarillas. Su ejercicio por agentes locales desencadenaría el caos y la anarquía, a menos que dependieran exclusivamente del Presidente de la República (Salazar y Pinto, 1999:35). Este sistema unitario y fuertemente centralizado estableció un primer límite a los proyectos de la elite: reservar buena parte de sus ventajas a Santiago, en evidente desmedro de las provincias.

En tercer lugar, se presumió que el país tenía suficientes fortalezas para trazar su futuro por sí mismo, de espaldas a cualquier proyecto panamericano o sudamericano. Nuestros grupos dirigentes actuaron, en este sentido, con una cierta soberbia, cerrándole el paso a los sueños bolivarianos o a cualquier proyecto de integración regional, como el del mariscal Santa Cruz. Estos mismos grupos imaginaron a Chile como un manantial de recursos que, bien aprovechados, nos permitirían salir adelante sin la ayuda de nuestros vecinos. 
Predominó una convicción insular, muy claramente expresada por el propio Diego Portales. ${ }^{6}$

En el plano de la economía se insistió en aprovechar las riquezas del territorio. Esto obligaba a traer hombres ilustrados de Europa que pudieran informar acerca de lo que el país tenía y sobre lo que le convenía hacer. Se insistió, por ejemplo, en la necesidad de estimular nuevos cultivos agrícolas, apoyar la minería, impulsar la industria, desarrollar el mercado interior y capturar los mercados externos que favoreciesen nuestro crecimiento económico. ${ }^{7}$ Al comienzo, no se pensó en aumentar el territorio, sino en aprovechar lo que ya se tenía. De este modo, el progreso se lograría con los recursos de la tierra y con la savia de los hombres ilustrados del Viejo Mundo que iluminarían el camino que en el futuro deberíamos recorrer los chilenos.

Respecto de la población, se reconoció — como ya hemos dicho- su escasez y limitada preparación. Para resolver ambos problemas se pensó en la educación e inmigración, sobre todo en la primera. La educación sería la palanca del progreso, concediéndosele una importancia práctica y moralizadora que nadie discutió. Por la educación seríamos buenos trabajadores y mejores chilenos. Alcanzaríamos las condiciones para que nuestra población, educada y cultivada, pudiera asumir la soberanía del poder y traspasarlo a sus representantes, convertidos en gobierno por la voluntad popular, principio que suscribió sin reservas la clase política en el siglo XIX.

\footnotetext{
${ }^{6}$ Esta idea, que en Portales es muy clara cuando se opone a la intervención de Estados Unidos y a la Confederación Perú-boliviana, se perfiló en nuestro país con anterioridad a los años 20. Hacia 1818, don José Miguel Carrera veía en Argentina un peligro, pues corríamos el riesgo de convertirnos en una obscura provincia de Buenos Aires. Cfr. "Manifiesto a los habitantes libres de los pueblos de Chile”, en Medina, III, 1964-1965: 224. Hubo opiniones, sin embargo, que percibían la unidad sudamericana como una buena alternativa para enfrentar a las potencias europeas. Así lo recomendaba, por ejemplo, el futuro Presidente de la República, Francisco Antonio Pinto, a Bernardo O’Higgins en oficio que le dirigió desde Tucumán en agosto de 1817: "No se duda, pues, que el seguro medio de consolidar la América, hacerla respetable y mantenerla tranquila es una confederación de todo el Sur americano”, decía Pinto, citado por Ricardo Montaner. Historia diplomática de la Independencia de Chile. Andrés Bello, 1961, 442. Años antes, la idea de una confederación de los países de la América Meridional ya había estado presente en El Catecismo Político Cristiano que circuló en 1811. Cfr. Walter Hanisch. El Catecismo Político-Cristiano. Las ideas y la época: 1810. Santiago de Chile: Andrés Bello, Santiago, 1970, 42.

${ }^{7}$ Uno de los primeros documentos que plantea una acción para el emergente Estado en Chile es el ya citado "Plan de Gobierno" de Juan Egaña, en 1810. Egaña proponía franquear el comercio, apoyar la industria, desarrollar la agricultura, fomentar la Marina y evitar la traída de negros, pues, en su opinión, eran viciosos y arrastraban a la plebe. Por lo mismo, se oponía a cualquier medida que favoreciese a las castas. Proponía, también, “uniformar la opinión pública a los principios del gobierno", cuidando que los empleados públicos antepongan sus miras personales.
} 


\section{Jorge Pinto Rodríguez}

La admiración por Europa y por lo europeo caló, también, muy profundamente en la conciencia de estos grupos. Poco a poco fuimos asumiendo una actitud de imitación que se traduciría, muy pronto, en un sueño largamente acariciado por nuestra elite: ser en América un rincón de Europa.

Con esta visión, e inspirados en los principios anteriores, el país se lanzó a la búsqueda del progreso. Chile tenía que desarrollarse por sí mismo, con un sistema político unitario y centralizado, bajo el estricto imperio del orden, aprovechando sus propios recursos, con el aporte de sabios extranjeros que ayudarían a explotar nuestras riquezas y mediante una educación que le permitiría a la población superar sus debilidades. Eran las claves que Portales y los grupos que rodearon su gestión, presumieron, garantizarían el logro de las metas propuestas para hacer de Chile una potencia en este extremo del continente. ${ }^{8}$ Estos mismos principios constituyeron la base de la gestión emprendida por los gobiernos de la época para insertar la economía chilena en la economía mundial. Desde luego, había que ordenar las finanzas, otorgarle confianza a los agentes económicos y, una cuestión vital, lograr el control del Pacífico. Buena parte de la gestión del ministro Manuel Rengifo se orientó en esa dirección, aunque no fue el primero en ocuparse de estas materias.

Estudios recientes han demostrado que el debate librecambismo versus proteccionismo no se planteó en términos excluyentes y que nuestros primeros economistas fueron, en este sentido, más bien prácticos. La mayoría comprendía que se debía proteger la industria nacional, aunque observaron que el comercio era un excelente medio para impulsar el crecimiento económico (A. Góngora, 1984; Villalobos y Sagrado, 1993). En cambio, en lo que existió consenso fue en la necesidad de garantizar la fe pública y la confianza de la gente. Esto quedó claro cuando se discutió la magnitud y la forma de cancelar la deuda pública, ya en tiempos del gobierno de O’Higgins. Desde el ministro Pedro Nolasco Mena hasta el ministro Manuel Rengifo, todos consideraron que, junto con organizar la hacienda pública y enfrentar los desajustes generados por la guerra de la Independencia, Chile debía responder a sus acreedores, tanto en el país como en el extranjero. El crédito [confianza] decía el Ministro Benavente en 1823, es "la fuente inagotable de riqueza para todos los estados” (Sagrado, 1997).

El control del Pacífico fue otra aspiración compartida desde los primeros años de la República por nuestra clase dirigente. En cierto modo, se puede afirmar que la economía chilena fue dirigida en sus comienzos por

\footnotetext{
${ }^{8}$ Sobre el pensamiento de nuestra elite en esta época, Cfr. Ricardo Donoso. Las ideas políticas en Chile. Santiago de Chile: Universidad de Chile, 1967, texto que mantiene vigencia, particularmente por la información documental que contiene.
} 
comerciantes y abogados que habían vivido en Argentina y Perú, los dos países que más importaban para orientar el destino del nuestro. La mayoría estaba de acuerdo en la importancia del comercio y, por lo mismo, en la necesidad de lograr el control del único medio por el cual podíamos desarrollarlo: el Océano Pacífico. Ya en 1809, Anselmo de la Cruz, futuro Ministro de Hacienda en 1818, aseguraba que el "comercio, unido a la agricultura y a la industria, es el principal nervio del Estado", demostrando una profunda admiración por Inglaterra, uno de los países que más se había distinguido en el comercio marítimo. ${ }^{9}$ La propia expedición libertadora al Perú, y el apoyo que dio nuestro país a su independencia, no estuvo desprovista del interés de garantizar el libre flujo de nuestros productos por el mar. La presencia de España en el Perú, decía Bernardo O’Higgins en una circular de 1821, amenazaba el porvenir y es "preciso abrir los caminos obstruidos a la exportación de sus frutos y a las esperanzas del propietario". ${ }^{10}$ Rodríguez Aldea, Ministro de Hacienda en 1820, hizo suya la idea de convertir a Valparaíso en el "entrepuerto" de América del Sur, aprovechando su posición privilegiada para los barcos que venían desde el Atlántico por el Cabo de Hornos y para los que navegaban por el Pacífico, cuando aún no existía el Canal de Panamá. ${ }^{11}$ Para lograrlo, era obvio que se debía conseguir la Independencia del Perú, cuyo comercio, en manos de españoles, sería un freno para los intereses de los comerciantes chilenos. Por costoso que resultara la independencia de nuestros vecinos del norte, Chile no tenía más opción que apoyar aquellos esfuerzos para despejar el camino. Insistentemente José Rodríguez Ballesteros en su Historia de la Revolución de la Independencia del Perú desde 1818 hasta 1826, deja en evidencia los intereses que estaban en juego (CHDICh, XXXII-XXXIII-XXXIV).

Rodríguez Aldea, cuyo conocimiento de la economía chilena lo distinguió durante los primeros años de la República, participaba plenamente de estas ideas. Para él, en el comercio estaba la clave del éxito. Sin embargo,

\footnotetext{
${ }^{9}$ Anselmo de la Cruz. "Memoria sobre la verdadera balanza del comercio que conviene al reino de Chile”, leída por el secretario del Consulado don Anselmo de la Cruz el 12 de enero de 1809, en Miguel Cruchaga. Estudio sobre la organización económica y la hacienda pública de Chile. Madrid: Reus, 1929, Tomo III, 400-416.

${ }^{10}$ Sobre el interés que despertó entre comerciantes y otros agentes económicos la expedición libertadora al Perú, para asegurar su independencia son muy interesantes diversos artículos aparecidos en El Censor de la Revolución en el curso de 1820. CAPCh, vol. IX. Santiago: Nascimento, 1960.

${ }^{11}$ Decreto de B. O’Higgins en adición al Decreto de Libre Comercio de 1813, Santiago, 30 de septiembre de 1820, en Escritos y documentos del Ministro de O'Higgins, doctor José Antonio Rodríguez Aldea y otros concernientes a su persona, en Colección de Historiadores y de Documentos relativos a la Independencia de Chile (en adelante $\mathrm{CHDICh}$ ), tomo XXXV, Santiago: Cultura, 1950, 555.
} 


\section{Jorge Pinto Rodríguez}

no bastaba darle la atención que merecía; en su opinión, debía ir acompañado de otras medidas que lo fortaleciera. Así, por ejemplo, en una memoria de 1822 proponía traer inmigrantes que aportaran laboriosidad; controlar el contrabando y, por sobre todo, cerrar las fronteras a los productos extranjeros que competían con los productos chilenos. No cabe dudas que el proteccionismo de aquellos años se basaba en las potencialidades que nuestros economistas atribuyeron al comercio, sin el cual la industria nacional no tenía destino (Váliz, 1961).

Conseguida la Independencia del Perú, la experiencia de los comerciantes que habían incursionado en aquel país, entre quienes destacan Pedro Nolasco Mena y el propio Portales, los convenció de que el paso siguiente era evitar que nuestros vecinos asumieran un rol hegemónico en los mares del sur, intención que queda de manifiesto en toda la documentación de la época, a pesar de que en 1822 se firmara con sus autoridades un Tratado de Colaboración y Apoyo Mutuo, que podría desmentir las intenciones más íntimas de quienes empezaban a manejar nuestra economía (CHDICh XXXVI:110,113). Si queríamos crecer por nosotros mismos y de la mano del comercio, teníamos que doblegar a Perú y estimular las exportaciones cuanto fuera posible. Para eso se requería orden, un poder fuerte y centralizado y una administración eficiente. Portales se habría valido, precisamente, del "peso de la noche” para lograr esos objetivos. La enemistad que manifestó hacia Perú y la Guerra que impulsó en 1836 contra el mariscal Santa Cruz refleja hasta dónde podía llegar nuestra clase dirigente en sus esfuerzos por lograr las metas que se propuso.

Benjamín Vicuña Mackenna asoció al Ministro de Prieto a la más rancia reacción colonial, dictatorial y aristocratizante, aunque no pudo desconocer que se trató de un hombre práctico, forjado en el ejercicio del comercio, cuyos secretos conocía por su experiencia en Lima y Valparaíso. Esa experiencia lo convenció que, tarde o temprano, Chile debía someter a Perú y mantenerse atento a la intervención de Estados Unidos. Su célebre carta a José M. Cea (Lima, marzo de 1822), en la cual expresa sus temores frente a la política expansiva de este último país, refleja cabalmente la inquietud de un comerciante chileno que no quería competir con otra potencia en los mares que se debían controlar desde Valparaíso (Vicuña Mackenna 1936, 1937). Si los juicios de Vicuña Mackenna sobre la guerra contra Santa Cruz son correctos, ésta tenía una sola explicación: la voluntad inflexible de Portales de evitar cualquier peligro para los afanes de Chile de dominar sin contrapeso en el Pacífico sur. "Estaba persuadido — dice Vicuña Mackenna— de que la Confederación Perú-Boliviana era un peligro para Chile y estaba 
resuelto a correr todo albur para desvanecer aquella sombra” (1937:359). ${ }^{12}$ Encina corrobora este juicio. Según él, uno de los pilares de la concepción política de Portales se inspiraba en la necesidad de asegurar el predominio de Chile en el Pacífico, para lo cual se debía bloquear cualquier amenaza que impidiera el logro de este objetivo, como el eventual fortalecimiento del Perú (Encina, 1937).

\section{EL PRIMER AJUSTE DE CUENTAS: LOS JÓVENES DEL 40}

En 1842, Claudio Gay expresó en Francia opiniones muy lisonjeras sobre Chile. Entre las repúblicas sudamericanas, escribía el sabio francés,

"hay una, Chile, que tomando un impulso extraordinariamente rápido en todas las ramas de la civilización, parece sustraerse pronto a los prejuicios nacionales y ponerse al nivel del progreso de la vieja Europa. Emancipada desde hace más de veinticinco años del gobierno español, ha debido sufrir esas fases de revoluciones y aun de anarquía que son las consecuencias naturales de esos grandes movimientos políticos; pero gracias al espíritu de orden y de tranquilidad, se ha restablecido el equilibrio y este país que antes era mirado casi como una provincia del Perú, desempeña hoy un papel de primer orden y ofrece al Nuevo Mundo un magnífico ejemplo de progreso y prosperidad”. ${ }^{13}$

Que todo, en efecto, agregaba más adelante,

"parece favorecer el porvenir de este afortunado país. Su situación geográfica y sus ricos productos agrícolas atraen a sus costas todo el comercio extranjero y han hecho de Valparaíso un depósito general a donde vienen a proveerse todos los comerciantes de las repúblicas vecinas. Sus ricas minas de oro, de plata y de cobre aumentan diariamente sus recursos y su industria, aunque naciente, parece querer tomar una parte muy activa en esta gran regeneración. La forma y disposición del terreno no contribuyeron menos al desarrollo de esta industria: bañada en toda su longitud por un mar profundo, con puertos grandes y seguros, posee además grandes ríos que, despeñados de lo alto de la cordillera, llevan consigo una rapidez y por consiguiente una fuerza motriz inmensa, incalculable, elemento de riqueza en extremo

\footnotetext{
12 Vicuña Mackenna descarta que la expedición de Freire desde el Callao a Chile con la intención de recuperar el poder, en las luchas intestinas que se generan después de la independencia, haya sido promovida por el Mariscal Santa Cruz.

13 "Fragmento de un viaje a Chile y el Cuzco, Patria de los Antiguos Incas", texto leído en la Sociedad de Geografía de París en su sesión general del 30 de diciembre de 1942, en Carlos Stuardo. Vida de Claudio Gay, 1800-1873. Santiago: Nascimento, 1993. Tomo II, 293-306.
} 


\section{Jorge Pinto Rodríguez}

importante y preferible a veces al que nos dan las grandes máquinas a vapor, cuyas ventajas están a menudo controladas por los gastos de compra, conservación, reparación y combustible. El mismo gobierno no permanece indiferente a esta gran obra: lleno de moralidad y de buenas intenciones, ha dado un gran desarrollo a su organización interior y ha elevado su crédito a una altura tal que le hará pronto marchar casi de frente con las naciones más favorecidas de Europa; ejemplo único en la América española y que por sí sólo resume toda la historia de sus progresos y de su porvenir” (294).

"Los grandes problemas sociales no se han descuidado. Aquellos que son del dominio de la instrucción popular y que tienden a mejorar la condición de la masa de los habitantes no han sido descuidados. Cada día se multiplican las escuelas primarias y con el objeto de promoverlas se ha fundado en Santiago una Escuela Normal, cuyos jóvenes alumnos deben recibir una instrucción muy especial, para dirigir más tarde las de las clases inferiores. Los establecimientos literarios y científicos no son menos dignos de su buena intención. En las provincias se han establecidos algunos liceos con profesores nacionales o extranjeros, de un mérito muy reconocido y en la capital hay un buen número de establecimientos que no despreciaría nuestra alta ilustración. Cuando solamente algunos años han bastado para enriquecer esta capital con excelentes internados, con una Biblioteca tan rica como bien acogida, con un Gabinete de Historia Natural, que ni siquiera estaría fuera de lugar en nuestras grandes ciudades de provincias, con un excelente Jardín de Aclimatación y con una Universidad que debe velar por todo lo que se relaciona con la instrucción; cuando se ven, digo, establecerse a la par Sociedades de Agricultura y de bien público y circular diarios, especialmente consagrados, unos a la literatura, otros a la legislación o a la agricultura, etc., se puede prever con certidumbre la alta posición que debe tener pronto este rico y dichoso país” (293-294).

Sin duda, los parisinos que acudieron a escuchar a Gay en aquel invierno de 1842 - y que algo habían escuchado de América del Surdebieron sorprenderse de los progresos alcanzados por Chile en un continente donde ningún otro país podía mostrar un panorama semejante. Por lo demás, señales provenientes de la economía parecían justificar los juicios del naturalista francés. Nuestra agricultura estaba en plena recuperación; la producción de plata se había elevado a niveles insospechados; habíamos resuelto el problema de la deuda interna y externa; había concluido exitosamente la guerra contra la Confederación Perú-boliviana; los ánimos políticos se habían calmado y el Estado empezaba a dar forma definitiva a su estructura y organismos de gobierno. Numerosos exiliados, la mayoría distinguidos intelectuales de países vecinos, y no pocos sabios europeos 
habían elegido a Chile como lugar de residencia, impulsando una febril actividad intelectual que animó a la sociedad nacional. En 1843 se practicó el segundo censo nacional, el primero dirigido por la Oficina de Estadística, establecida por decreto del 27 de marzo de 1843, gracias a la insistente preocupación del mismo Claudio Gay y a los requerimientos de las autoridades de contar con una institución que reuniera los datos que necesitaban para orientar su gestión. ${ }^{14} \mathrm{Al}$ momento de su creación el ministro del Interior, don Ramón Luis Irarrázabal, declaraba que "el conocimiento de la estadística de un país es la base indispensable para graduar sus progresos, atinar con los obstáculos que los enervan, y calcular con acierto las convenientes medidas administrativas”. ${ }^{15}$ Según el censo, 1.081.494 habitantes vivían en aquel remanso que Claudio Gay describió en París. Un año antes, en el primer mensaje que el presidente Bulnes dirigió al Congreso, destacó que nunca antes, “desde el primer día de la independencia, en ninguna de sus fases hallaremos como hoi se presenta a nuestra vista, tan bien cimentado el orden, tanta armonía entre los gobernantes y gobernados, tanto respeto a las instituciones, ni tanto celo por la conservación del inapreciable bien de la paz doméstica” (Barros Arana, 1913 I: 269).

¿Qué tanto había de cierto en los juicios de Gay y del presidente Bulnes? Las apariencias demostraban que Chile había logrado una estabilidad política y económica que nadie podía desmentir. Sin embargo, una serie de señales casi imperceptibles daban cuenta de algunas inquietudes que en los años siguientes cobrarían más fuerza.

Las primeras brisas soplaron al interior del Instituto Nacional en abril de 1839 en torno a la figura de José Victorino Lastarria y de un grupo de profesores que iniciaron debates académicos, a los que se sumaron algunos estudiantes. La llegada de inmigrantes argentinos que escapaban de las turbulencias políticas de ese país contribuyó a estimular la agitación intelectual y algunos episodios aparentemente intrascendentes generaron también, cierta inquietud. Diego Barros Arana recuerda un hecho del cual reconoce no quedar otro rastro sino el de su propia memoria, provocado por

14 Rolando Mellafe. Introducción al XII Censo General de Población y I de Vivienda, levantado el 24 de abril de 1952. Servicio Nacional de Estadística y Censos, Santiago: 1956, 23. Mellafe recordó que Gay no sólo recomendó crear esta Oficina, sino un Archivo General "para reunir en una sola oficina todos los preciosos documentos que hoy día se hallan esparcidos en varias administraciones y algunas veces con grande peligro de echarse enteramente a perder”. Sobre el rol que le correspondió a Gay en la formación de esta Oficina y en la política de la época, Cfr. Luis Mizón. Claudio Gay y la formación de la identidad cultural chilena. Santiago: Universitaria, 2001.

${ }^{15}$ Diego Barros Arana. Un decenio de la Historia de Chile. Santiago: Imprenta, Litografía i Encuadernación Barcelona, 1913, tomo I, 367. El encargado de la organización de esta oficina fue don Fernando Urízar Garfias. 


\section{Jorge Pinto Rodríguez}

un aventurero norteamericano que prometió elevarse en un globo en la plaza de armas de Santiago. El fracaso de su promesa concluyó en una suerte de motín popular que fue seguido de otros en Valparaíso por cuestiones políticas, que contrastaban con las señales de armonía que describían Gay y Bulnes ${ }^{16}$ (Barros Arana, 1913 I: 96).

En 1840 empieza a circular en Santiago La Guerra a la Tiranía, periódico que en nada se diferenciaba de otros de carácter político que habían circulado antes, pero, incubado ahora en un clima de oposición más radical al gobierno que en años anteriores. El año 1842 se funda la Sociedad Literaria y, ese mismo año, sus miembros denuncian que Chile carece de soberanía popular, democracia e ilustración. Lastarria, en su condición de director del movimiento, fue muy preciso al ratificar lo anterior: Chile necesita una democracia que no pudieron cultivar los padres de la patria y una educación que contenga los vicios sociales. "Hemos tenido la fortuna de recibir una mediana ilustración —escribió Lastarria—, pues bien, sirvamos al pueblo, alumbrémosle en la marcha social para que nuestros hijos le vean un día feliz, libre y poderoso". ${ }^{17}$ En el $\mathrm{N}^{\circ} 2$ de El Crepúsculo, aparecido el 1 de junio de 1844 (52-90), Francisco Bilbao publica su famosa Sociabilidad Chilena que remeció a la elite santiaguina. ${ }^{18}$ Sarmiento criticó duramente los planteamientos de Bilbao, señalando que Sociabilidad Chilena era una mezcla indigesta de desatinos y herejías (Jalif, 2003; Sánchez y Corrales, 1996; Donoso 1940), aunque no pudo ocultar el revuelo que provocó en Santiago. Por esos mismos días, la aparición de la obra de Gay generó nuevos debates. José Victorino Lastarria, convertido ya en un influyente profesor del Instituto Nacional y de la recién fundada Universidad de Chile, publicó en el primer número de los Anales un ensayo sobre la influencia del sistema colonial en nuestro país que dejó entrever fuertes críticas a la situación política del país

\footnotetext{
${ }^{16}$ El episodio del norteamericano fue comentado también, siguiendo a Barros Arana, por Cristián Gazmuri en El 48 chileno. Igualitarios, reformistas, radicales, masones y bomberos. Santiago: Universitaria, 1999, 53-54.

${ }^{17}$ Citado por Nicolás Ocaranza. "La conciencia crítica de un joven liberal chileno”, en Juan Luis Ossa y otros. XIX. Historias del siglo diecinueve chileno. Santiago: Vergara Grupo Zeta, 2006, 98-130, 109.

${ }^{18}$ Bilbao asociaba al presidente Manuel Bulnes al pasado colonial, identificándolo con el guaso u hombre del sur, influenciado también por el indígena, y conservador por naturaleza. Para los jóvenes, el desafío era retomar la revolución y aplastar la síntesis autoritaria, respaldados en la democracia, la educación y la propiedad. Para contrarrestar la influencia de la iglesia, proponía profundizar la religión científica. Sociabilidad Chilena fue publicada, también, por Francisco Bilbao en América en peligro. Santiago: Ercilla, 1941, 72-124.
} 
(1846: 199-271). ${ }^{19}$ Paulatinamente, los debates académicos y literarios dieron paso a discusiones políticas que cuestionaban con aspereza el modelo político, económico y social que Bulnes heredara de Prieto. El proyecto de Portales recibía, así, las primeras críticas surgidas al interior de la propia elite, formuladas por jóvenes inquietos que veían con preocupación el abandono de los ideales que, según ellos, habían inspirado la independencia. De acuerdo a sus juicios, se habría producido en Chile una transición que siguió caminos inesperados y una especie de traición que ellos se proponían enmendar.

En los años siguientes, los conflictos se fueron haciendo más complejos. Según Cristián Gazmuri, cuatro circunstancias provocaron, al término del gobierno de Bulnes, una coyuntura que agudizó la situación. En primer lugar, la fuerza que cobrara entre los jóvenes ilustrados de la elite una postura antiautoritaria, que rechazó el intervencionismo electoral y las pretensiones del gobierno de colocar a don Manuel Montt en la presidencia de la República como sucesor de Bulnes. En segundo lugar, la expansión de Santiago que favoreció la formación de un artesanado que hacia 1850 oscilaba entre los 10 y 15 mil trabajadores, la mayoría surgida por demandas urbanas que se vieron afectadas por la ampliación de un comercio que abrió las puertas a productos europeos. En tercer lugar, la riqueza generada por el oro californiano que terminó acentuando un espíritu especulativo resistido por los jóvenes. Por último, las noticias que llegaban de Europa y los movimientos de París de 1848 fueron la mecha que encendió la hoguera ${ }^{20}$ (Gazmuri, 1999:46).

La mayoría de los jóvenes que participaban de este espíritu de cambio fundaron en octubre de 1849 el Club de la Reforma, uno de cuyos principales objetivos fue impedir el triunfo de Manuel Montt en las elecciones presidenciales que se realizarían en 1851. Al año siguiente, los mismos jóvenes, a los cuales se sumaron algunos artesanos, dieron forma a la Sociedad de la Igualdad, con la clara intención de intervenir en la política contingente. Una de sus figuras más sobresaliente fue Santiago Arcos Arlegui, un joven que regresaba de París con los ánimos henchidos por lo que había presenciado a orillas del Sena en los meses previos a las revueltas de ese año, en un ambiente convulsionado por el socialismo utópico, las ideas

\footnotetext{
19 José Victorino Lastarria. "Investigaciones sobre la influencia social de la conquista i del sistema colonial de los españoles en Chile”, en Anales de la Universidad de Chile correspondientes al año de 1843 i al de 1844. Santiago: Imprenta del Siglo, 1846, 199-271.

${ }^{20}$ El impacto de los acontecimientos de París del año 1848 marcaron un hito en el pensamiento y acción reformista no sólo en Chile, sino en buena parte de los países europeos y latinoamericanos. Todavía hoy el Partido Socialista chileno, como otros partidos socialistas del mundo, entona como su himno la Marsellesa Socialista, inspirada en los acontecimientos de 1848, que tanta admiración provocaron a Marx. Cfr. E. J. Hobsbawn. Los ecos de la Marsellesa. Barcelona: Crítica, 1992.
} 


\section{Jorge Pinto Rodríguez}

democráticas-republicanas, el romanticismo y un cristianismo que volvía sus miradas al Cristo que predicó la fraternidad e igualdad (1989:13-15). Según José Zapiola, sus planteamientos fueron mucho más lejos de lo que pensaban los "ciudadanos" que formaban parte del grupo. Arcos sostenía que no bastaba derrotar a Bulnes, había que "sacar al pueblo de la vergonzosa tutela a que se le tiene sujeto" y ampliar las bases de una democracia por medio de un sistema próximo al socialismo (Zapiola, 1902: 8-9). Para lograrlo se había reunido en Santiago una juventud "ardorosa i de nobles aspiraciones", capaz de iniciar la regeneración política y social que Chile necesitaba. Junto a él estaban Eusebio Lillo, Manuel Recabarren, Benjamín Vicuña Mackenna, Manuel Guerrero, José Zapiola y Francisco Bilbao, el más influyente de todos a la hora de fundar la Sociedad de la Igualdad, bajo los principios de "libertad, igualdad y fraternidad” (Barros Arana, 1913 II:89).

No es propósito de este artículo relatar las vicisitudes de la Sociedad de la Igualdad y la represión de que fue objeto por parte de las autoridades, tanto en Santiago como en algunas ciudades de provincia, sino destacar algunas ideas que empiezan a cobrar fuerza y que ponen en tela de juicio las bases del proyecto modernizador de las elites de los años 20 y 30 . Al mismo tiempo destacar, cómo desde aquellas ideas algunos transitaron hacia fórmulas político-sociales que los acercaron a la génesis del socialismo chileno. El Amigo del Pueblo, el periódico de la Sociedad, difundió diversas ideas sustentadas en la justicia social y en el compromiso del Estado de atender las necesidades de todos los chilenos. En el terreno estrictamente político, su meta era impedir el triunfo de Montt, aunque siempre acompañaron aquella idea con la de introducir reformas al sistema que imperaba en Chile. Dos de sus figuras más notables, José Victorino Lastarria y Federico Errázuriz, ambos diputados, redactaron el 28 de octubre de 1850 un documento, denominado Bases de la Reforma, que contiene algunas ideas muy interesantes. Desde luego, rechazan la candidatura de Montt, a quien consideran continuador de una política nefasta para el país. A pesar que reconocen que la Constitución de 1833 fue útil en su tiempo, comparten la idea que su vigencia - bajo las actuales circunstancias- es absolutamente inadecuada y no reparan en señalar que "el poder político del Estado de Chile no es el patrimonio de un individuo, ni de una familia, ni de una clase privilegiada”, sino de todos los chilenos. Partidarios de proteger la industria nacional, sus voces insinúan aires de cambio en un país, que - tal como lo denunciará más adelante Santiago Arcos - estaba exclusivamente al servicio de los ricos (1850:9).

Bernardo Subercaseaux llamó a esta generación la de los “déspotas ilustrados”, que se sintieron más importantes que los Padres de la Patria y se creyeron fundadores de una nueva nación (Jalif, 2003:83). También se ha 
dicho que asumieron la misión de pensar el país y contribuir a modificar la sociedad, tratando de organizar un poder centrado en ellos mismos (Stuven, 2000; Figueroa, 2004). Estos juicios retratan muy bien a la llamada “generación del 42”, la primera en levantar una propuesta alternativa al primer proyecto modernizador de nuestra elite. Y fueron, precisamente, los sucesos políticos del año 1851 los que pusieron frente a frente los proyectos más conservadores de la vieja elite chilena con las propuestas liberales de los jóvenes, pertenecientes a la misma elite, que se formaron en los años 40 .

Parecíale a la juventud de aquella edad — escribe Vicuña Mackenna¡ai!, harto diversa de la que hoi se agrupa en torno de los poderes públicos, que asistía como por encanto a un período de resurrección i de milagros. Las dos décadas llamadas de Portales, que acababan de pasar con sus hombres, sus reacciones i sus castigos, habían dejado en los espíritus esa amortiguada y temerosa confusión, legado de esos gobiernos fuertes que hacen muchas veces grandes cosas en las finanzas, en la guerra, en la administración, en las leyes mismas, pero que abaten el espíritu de las jeneraciones, i como las nieblas matinales del otoño, no dejan divisar el claro sol sino a lampos (1878:13).

El propio Vicuña Mackenna recuerda cuánto pesó en esta generación los movimientos de París de 1848 y la enorme influencia de los Jirondinos, “obra primorosa i a la vez gigantesca”, que levantó más barricadas en Europa que los pavimentos de sus capitales. El mismo escribió los Jirondinos chilenos para emular en Chile las proezas de aquellos jóvenes. En un país “copista i reproductor”, concluye Vicuña Mackenna, era imposible resistir la potente oleada que llegaba del Viejo Mundo (1878: 17-18).

¿Qué es lo medular de este primer ajuste de cuentas que los jóvenes de la elite formulan a quienes habían organizado el Estado nacional y elaborado el proyecto político, económico y social que se instala con Portales? Un análisis de los textos de la época y los acontecimientos que se precipitaron a partir de 1840 permiten sugerir que se cruzaron, en esa coyuntura tan particular que describió Gazmuri, por lo menos seis demandas.

En primer lugar, hay un evidente interés por distanciarse de España y erradicar todos los resabios del viejo sistema colonial que los jóvenes del 40 creen se reinstala en Chile con los gobiernos de Prieto y Bulnes. La fuerte resistencia hacia la candidatura de Montt refleja los temores de estos jóvenes de ver entronizado para siempre un sistema que, muy poco, se apartó de aquél que mantuvo al continente en la penumbra intelectual durante toda la colonia.

Este distanciamiento de España va asociado, también, a un fuerte cuestionamiento de la intervención de la Iglesia en los asuntos del gobierno, ya la que considera un dique de contención para los cambios que quieren 


\section{Jorge Pinto Rodríguez}

impulsar. Los ojos de los jóvenes están puestos en una Europa moderna, liberal y, sobre todo, guiada por los principios de la razón.

Su segunda demanda era, precisamente, instaurar la soberanía de la razón científica. Bilbao fue el más explícito de todos. Hasta esos años —escribe Bilbao - las inquietudes de la humanidad se habían satisfecho por medio de una fe basada en la religión. El mundo del futuro debe construirse desde una filosofía crítica que acuda a la ciencia para iluminar el porvenir. Sólo esta actitud hará libre a los pueblos y los salvará de la esclavitud a que fueron sometidos cuando la religión dominó los espíritus. Recuperaremos, así —agregaba Bilbao - el paraíso de la libertad por la que se luchó durante la Independencia y de la cual fuimos despojados ${ }^{21}$ (1844:73-75).

Ésa fue, justamente, la tercera demanda: la recuperación de la libertad. Una de las grandes pérdidas de la década anterior había sido la libertad. Portales fue presentado como la reacción conservadora más extrema y su ministerio como el responsable de la pérdida de ese bien. La propia Constitución del 33, que había respondido a las exigencias de la época, debía ser reformada para dar paso a otra que garantizara la libertad.

La cuarta demanda era de carácter diferente. En los años 40 adquirió fuerza una cierta sensibilidad social que llevó a los jóvenes a adoptar una posición antiaristocrática, cuyos orígenes se encuentran en el liberalismo de los años 20, encabezado por figuras como Nicolás Pradel y Manuel Magallanes. Ya en esa época, ambos proponían que la revolución tuviera "un carácter franco, claro y popular”, apelando a Freire e Infante para lograr sus propósitos (Collier, 1977: 337-339). Sin embargo, sería Santiago Arcos quien llegaría más lejos en esta demanda, vinculando sus posturas a un socialismo que conoció en Europa y que radicalizó más adelante. Sin duda, la famosa carta que escribió a Bilbao desde la cárcel de Santiago en la cual denuncia los males de un país en el cual cien mil ricos explotan a 1.400 .000 pobres, es uno de los documentos más interesante para escudriñar la dimensión social del movimiento gestado por la generación del 40. El Amigo del Pueblo, el diario que publicara la Sociedad de la Igualdad en 1850, fue un diario de combate que recogió parte de estos postulados. Acerca de sus fines, en el $\mathrm{N}^{\circ} 1$ señalaba, según cita Silva Castro

Su título dice su objeto. Al proclamar más libertad, más justicia, se hará el acusador tenaz de los hombres que estorban hoy en Chile el movimiento social. El Amigo del pueblo viene a ser el eco de una revolución que se agita en estos instantes sobre nuestras cabezas;

\footnotetext{
${ }^{21}$ Bilbao profundizó estos planteamientos en El Evangelio Americano. Buenos Aires: Imprenta de la Sociedad Tip. Bonaerense, 1864. En esta última obra insistió en su antihispanismo y en su adhesión a un sistema republicano basado en la autoridad de la conciencia y la razón.
} 
revolución pacífica y santa que nos dejará bienes inmensos y un horizonte político sereno y extendido (1958:205-206).

A las demandas anteriores, se sumó una quinta: lograr para las regiones un trato más justo. En los años 20, el federalismo había interpretado el sentir de la gente de Concepción y Coquimbo frente al control que empezaba a ejercer Santiago. Desde este punto de vista, no cabe duda que la Revolución de 1851 retomó esa demanda, trasformando a Concepción y La Serena en los focos más conflictivos del movimiento. Aunque éste es un tema menos trabajado, el modelo portaliano favoreció a la capital en desmedro de las regiones, cuyas aspiraciones agitaron los jóvenes de aquellos años. ${ }^{22}$

Por último, la generación del 40 insistió en la necesidad de apoyar a la industria nacional. Nadie dudaba de los beneficios del comercio exterior. Sin embargo, no pocos pensaban que aquélla necesitaba del apoyo del gobierno. Como lo han demostrado Villalobos y Sagredo, el proteccionismo nunca se abandonó en Chile. El liberalismo se impuso, más bien, por las ventajas de un sistema que aprovechó la expansión del comercio internacional y los altos precios que el mercado mundial ofrecía a las materias primas que se exportaban desde América, aunque no por eso se renunció a la idea de ampliar el mercado interior y favorecer la producción nacional. La polémica más interesante se produjo a propósito de la crisis de 1857, oportunidad en la cual varios representantes de la elite se mostraron partidarios de modificar el modelo exportador para sostener el desarrollo de Chile en el mercado nacional (Pinto, 1992; Salazar y Pinto, 1999:20-35).

A nuestro juicio, Mario Garcés ha realizado uno de los análisis más interesantes sobre los cuestionamientos y movilizaciones de los jóvenes del 40. Garcés sostiene que ésta fue la primera generación que apeló a los sectores populares, que puso de relieve nuevas vertientes del pensamiento político y que acogió postulados democráticos que más tarde serían asumidos por los partidos Radical y Demócrata. Se debatieron, además, proyectos de mejoramiento económico y cultural, se enfatizó en la pedagogía popular y se sentaron las bases de lo que podríamos llamar "sociabilidad obrera”, aunque el propio Garcés agrega que mostró sus límites al ignorar a la mayoría del pueblo que no era artesano. Los igualitarios del 50, concluye Garcés, no tenían ninguna propuesta que hacer a la masa turbulenta que recorrió las calles de Santiago aquel domingo 20 de abril de 1851 (1993:26-27). Daniel

\footnotetext{
${ }^{22}$ Recientemente, Luis Ortega ha publicado un interesante artículo en el que se refiere a estas demandas y a sus límites. A su juicio, los líderes regionales no estuvieron dispuestos a extremar sus peticiones al punto de poner en peligro un sistema global que, aunque perjudicaba a las regiones, les aseguraba las condiciones para mantener las hegemonías locales que habían logrado.
} 


\section{Jorge Pinto Rodríguez}

Riquelme, el autor del texto con que iniciamos este artículo, lo expresó de un modo más directo: “¿Por qué mueren los de abajo en estas querellas de nosotros los de arriba?”, se preguntó uno de los dirigentes de la revuelta al ver caer a un soldado de la tropa. Los artesanos - agregó Riquelme- fueron "arrastrados, compelidos a combatir sin saber hacer uso de las armas, por una negociación política en la que no tenían derecho alguno”. El pueblo, el pililo, llegó deshilachento, pidiendo armas y plata sin saber por quién pelear (1996:70, 146-179). El modernismo liberal de aquellos años. En opinión de Gabriel Salazar, el fue disolvente y terminó produciendo una gran masa marginal que su proyecto no pudo incluir (1992:114).

Argentina —escribió Nicolás Shumway- fue un país de opositores, responsabilizando de esta actitud a la generación del 37, algunos de cuyos representantes se desplazaron a Chile, donde ejercieron fuerte influencia en los jóvenes del 40 (1993:12). Aquí, no se podría decir que esos jóvenes inauguraron esta tradición. Desde las viejas disputas entre O’Higgins y Carrera, pasando por las luchas políticas de los años 20 y la posterior resistencia a Portales, la oposición fue siempre una práctica cotidiana que se expresó de múltiples maneras, especialmente en un periodismo incisivo y de trinchera que dio cuenta de un cierto desencanto y sensación de metas no alcanzadas. Aunque los jóvenes del 40 no modificaron esta tendencia, incorporaron aires frescos a la oposición, introduciendo elementos novedosos que los colocó a la vanguardia de la época y en la génesis de las movilizaciones sociales. De este modo, el viejo proyecto portaliano empezaba a nutrirse del aporte de nuevos contenidos, muy propios todavía de la elite, aunque mirando hacia sectores más amplios de la sociedad que seguían marginados y sin poder alcanzar los beneficios que soñaron las minorías que gobernaban Chile.

Curiosamente, años más tarde, miembros de esta generación expresaron su escepticismo frente a los acontecimientos políticos que se produjeron después de las movilizaciones de la década del 50, reconociendo cuan difícil era concretar los proyectos que nos conducirían al progreso. En 1868, José Victorino Lastarria, el maestro de los jóvenes del 40, señalaba que en Chile "los gobiernos bajan desacreditados para ceder su lugar a otros que suben a desacreditarse". Ese año Lastarria proponía como única solución la "semecracia" o gobierno por sí mismo, al estilo del "self-government" norteamericano (1968:3). En nuestra opinión, esos juicios sólo demostraban cuan difícil era lograr las metas cuando éstas se diseñaban al amparo de esperanzas e ilusiones que poco tenían que ver con nuestra realidad. 


\section{LOS RETORNADOS DE EL FERROCARRIL}

La semilla que sembró la generación de los 40 maduró en los años 60 al calor de las experiencias de los jóvenes que viajaron a Europa, exiliados por las contiendas políticas o atraídos por el embrujo de ese continente. Allá pudieron empaparse de las nuevas corrientes de pensamiento que recorrían el Viejo Mundo. La mayoría empezó a volver a mediados de los 50, una vez aquietados los ánimos y superadas las turbulencias del año 51.

Después de la Independencia, Europa —y Francia en particularfascinó a los jóvenes chilenos, tal como ocurrió en casi todos los países latinoamericanos. En Chile, uno de los primeros en viajar fue don Mariano Egaña, enviado a resolver los problemas heredados por el empréstito conseguido en Londres por José Antonio Irisarri. Nacido en 1793, bordeaba los 30 años al partir. Permaneció cerca de cinco años en Londres, y quedó deslumbrado por la cultura que observó en Europa

Muy defectuosa habría quedado mi educación política si yo no hubiese venido a Francia - decía a su padre en carta escrita desde París el 16 de febrero de 1828-, porque es preciso observar estas dos grandes naciones vecinas y compararlas. De esta comparación resulta que se penetre uno prácticamente de ciertas grandes verdades políticas, cuyo conocimiento es indispensable para servir a la patria con provecho (Donoso 1967:76).

A partir de entonces, viajar a Europa se convirtió en una obsesión para los jóvenes de nuestra elite. El primer viaje al Viejo Continente era un ritual de iniciación al que ningún joven de familia pudiente, de Santiago o de provincia, estaba dispuesto a renunciar. De acuerdo a una reciente investigación, ese viaje se hacía con la esperanza de encontrar allá las herramientas para avanzar hacia una "emancipación mental” del colonialismo peninsular. El interés de comparar lo que se observaba en Europa con lo que ocurría en América tenía un solo fin: dar cuenta del progreso de los territorios visitados para proyectarlo a sus respectivos países. ${ }^{23}$ Todos quedaron sobrecogidos por lo que vieron allá. Los que volvían sólo querían irse de nuevo o "vivir a la francesa" a orillas del Mapocho o de las polvorientas calles de las ciudades provincianas. ${ }^{24} \mathrm{~A}$ toda costa buscaban similitudes con

\footnotetext{
${ }^{23}$ Carlos Sanhueza. Chilenos en Alemania y alemanes en Chile. Viaje y nación en el siglo XIX. Santiago: LOM-DIBAM, 2006, 87-88. Entre las pp. 95 y 109, Sanhueza establece una interesante tipología de los viajeros chilenos, muy útil para quienes tengan interés en el tema.

${ }^{24}$ La reciente publicación del libro de Francisco Javier González Errázuriz. Aquellos años franceses. 1870-1990. Chile en la huella de París constituye el aporte más valioso sobre este
} 


\section{Jorge Pinto Rodríguez}

Europa, tratando de imaginarse que vivían en un país como aquéllos que habían visitado. Carlos Orrego Barros recuerda una anécdota que involucra a Diego Barros Arana, la que refleja la actitud de estos jóvenes en su afán por ocultar sus raíces y presentarse a la faz del mundo con un ropaje más propiamente europeo. Su patriotismo, cuenta Orrego, sufrió lo indecible cuando a su paso por París, en 1860, observó cuán poco se sabía de Chile y cuántos errores circulaban sobre el país

A veces en esas reuniones, escribe Orrego, su patriotismo tenía que sufrir; iy no poco! con las conversaciones de aquellos intelectuales. Muchas veces le oí contar que un miembro del Instituto de Francia queriendo ser amable con él, le preguntó: “¿Qué tal gobierno hacen en su tierra los araucanos?” A su respuesta insistió: “¿Que no tomaron el gobierno los araucanos?” Si no tomaron, “¿qué ganaron con la Independencia?”. Recordele, me decía, la Independencia de los Estados Unidos y entonces me preguntó: “¿Que su presidente es blanco?” Y yo, agregaba, tuve que sostenerle que "el Presidente Montt era muy blanco y de formas apolíneas... ¡A lo que obliga el patriotismo!” (1952:101102)

Francia se convirtió en el modelo a imitar y aunque muchos de estos viajeros se dieron cuenta del lado oscuro de los países europeos, no dudaron en que el único camino para salir del yugo español y alejarse del oscurantismo colonial era seguir el paradigma del liberalismo que se respiraba en la Europa al norte de los Pirineos (González, 1987:154). Allá palpitaba el corazón del mundo

Estaba ya en París, escribe Vicuña Mackenna en 1854, realizando el sueño de la mitad de mi vida y la imaginación adormecida otra vez en nuevos sueños de admiración y portento. Estaba en la capital del mundo, el corazón de la humanidad en que todo parece latir con las pulsaciones gigantescas que el espíritu de todos los pueblos envía a este centro de vida e inteligencia. Miniatura del Universo, aquí existe todo lo creado.

Hasta en la arquitectura el afrancesamiento se apoderó de nuestro país. Gonzalo Vial recoge el testimonio del viajero Teodoro Child, sorprendido por la falta de autenticidad de los edificios santiaguinos. Child encontró suntuosos edificios, aunque carentes de originalidad. Los había de estilo pompeyano, Tudor y turco-siamés, con cúpulas y minaretes. El Palacio Cousiño le pareció

punto. Un estudio pionero fue el de Jean Pierre Blacpain. “Cultura francesa y francomanía: el caso de Chile”, en Cuadernos de Historia No 7, Santiago (1987): 11-52. 
el más lujoso de todos, pero proyectado por un arquitecto francés y decorado y amoblado por artistas y artesanos franceses, a centenares de millas de Europa, con absoluto menosprecio de lo que ofrecía Chile (Vial 2006, I:19).

Armando Donoso recuerda las tertulias de los jóvenes retornados y cómo se fueron aglutinando en torno a El Ferrocarril, diario que les ofreció un espacio para exponer sus ideas (1935:177-200). Inicialmente, se trataba de un diario de tendencia conservadora, nacido para apoyar al presidente Manuel Montt, bajo la dirección de Ramón Sotomayor Valdés. Sin embargo, la llegada de Justo Arteaga Alemparte, a poco de fundarse, le cambió en parte su línea editorial y le abrió un espacio a los jóvenes rebeldes de los años 40 que volvían a Chile más maduros después de sus experiencias europeas (Silva Castro, 1958:211-213). En aquellas reuniones se hablaba de política, literatura, economía y de todo cuanto podía interesar a intelectuales de cuidadosa formación e interesados en los destinos del país. La Revista de Santiago, fundada casi junto con El Ferrocarril, les amplió la tribuna y les permitió desarrollar mejor sus ideas. ${ }^{25}$ La obligación de seguir pensando Chile y autoproclamarse los salvadores de la nación era para ellos irrenunciable, y más ahora que habían incorporado experiencias novedosas que les permitían definir horizontes con más claridad.

La crisis económica de 1857 y la ocupación de la Araucanía les brindaron una excelente oportunidad para desplegar sus reflexiones, recogidas en El Ferrocarril y en La Revista de Santiago, en cuyas páginas se fueron perfilando los proyectos de la nueva elite. El Mercurio de Valparaíso y las cátedras universitarias ampliaron sus ámbitos de debate. Convencidos que Chile tenía un solo camino -incorporase al progreso- adhirieron sin condiciones a un positivismo que cobraba, cada vez, mayor fuerza en todo el continente.

Universidad de La Frontera*
Departamento de Ciencias Sociales
Av. Francisco Salazar 01145
Temuco (Chile)
jpinto@ufro.cl

${ }^{25}$ Entre quienes asistían a estas reuniones pueden nombrarse a Alberto Blest Gana, José Antonio Donoso, Andrés Bello, José Victorino Lastarria, Benjamín Vicuña Mackenna, Eusebio Lillo y Diego Barros Arana, entre otros. Cfr. R. Donoso. "Un amigo de Blest Gana: José Antonio Donoso”, 154. 